\title{
A Contingency Model of Bidding Strategies in Online Auctions in China
}

\author{
Xiling Cui \\ The Department of Business Administration \\ Hong Kong Shue Yan University \\ Hong Kong SAR \\ xlcui@hksyu.edu \\ Lai Kuen Law \\ The Department of Business Administration \\ Hong Kong Shue Yan University \\ Hong Kong SAR \\ Iklaw@hksyu.edu \\ Paul Benjamin Lowry \\ The Department of Information Systems \\ City University of Hong Kong \\ Hong Kong SAR \\ pblowry@cityu.edu.hk \\ Qiuzhen Wang* \\ The Department of management science and engineering \\ Zhejiang University \\ Hangzhou, P. R. China \\ wqz@zju.edu.cn
}

\begin{abstract}
Online auctions have undergone rapid development in recent years. New features of online auctions, together with new bidding strategies different from those used in offline auctions, make research in this area compelling. The existing research mainly focuses on the description of bidding strategies; only a handful of studies focus on the antecedents of bidding strategies. This research aims to fill this gap by constructing a contingency framework to investigate why bidders bid differently in online auctions, and use unique bidding strategies. Environmental factors, bidding tasks, bidders' characteristics, and bidding motivations are included in the framework. We conducted in-depth interviews with professional, experienced bidders in China to reveal the specific reasons why bidders adopt different bidding strategies during online auctions. Finally, we discuss the implications for both global research and practice.
\end{abstract}

Keywords: Bidding strategies, Bidders, Online auctions, Qualitative research, China, Bidding motivations 


\section{Introduction}

Online auctions have seen rapid growth and successful development since the advent of eBay in 1995 (Stern \& Stafford, 2006). As a result, Amazon.com and Yahoo.com have also begun boosting their businesses through the use of online auctions. Several domestic online auction websites have emerged and are prospering in different countries, especially in mainland China. The Chinese people, who have little experience in offline auctions, have widely accepted the online auctions offered by Taobao.com, which dominates the consumer-toconsumer (C2C) electronic markets in China (Quaddus \& Achjari, 2005).

Park and Bradlow (2005) have given increasing attention to consumers' online bidding behavior, in which the realm of online auction bidding strategies has emerged as one of the most prominent topics. Researchers have found that bidders usually bid in certain patterns, which has given rise to the bidding strategy concept. This concept can be depicted in terms of when, how, how much, and how many times bidders submit their bids (Bapna, Goes, Gupta, \& Jin, 2004). Bidding strategies play a pivotal role in online auctions, as they may lead to different outcomes for bidders and sellers (Bapna et al., 2004).

Although there are some descriptions of bidding strategies in the literature, there is a lack of systematic research that investigates the antecedents of bidding strategies. Bidding is more complex than simple purchasing because the price is not fixed in auctions and people need to examine the current price, the bid increment, and the bidding behavior of other bidders during the bidding process. There are many studies in management information systems and marketing that have investigated the antecedents of purchasing (Chan, 2001; Devaraj, Fan, \& Kohli, 2002; Hong \& Cho, 2011; Tsiotsou, 2006; Wang, Yu, \& Wei, 2012). However, the reason why bidders choose different bidding strategies largely remains unclear to both the auctioneers and researchers. Therefore, it is necessary to investigate the antecedents of bidding strategy in online auctions. Furthermore, most of the literature discussed is Western in origin, and there are few examples of Asian studies in this area. Thus, there is a need to bridge the gap between previous studies under Western cultures and those in mainland China.

There are several bidding strategies that can be used in online auctions. Because the selection of different bidding strategies is a decision-making process, we use contingency theory. Contingency theory has been an important approach to the study of organizations and decision making (Elgharbawy \& Abdel-Kader, 2013; Kumar \& Subramaniam, 1997). Assuming contingency theory holds in this context, it would say there is no universally appropriate bidding strategy that is applicable to all situations. The choice of online bidding strategies therefore is contingent upon internal and external factors. Our study therefore leverages a contingency perspective to address this opportunity by constructing a comprehensive framework that reveals the antecedents of online auction bidding strategies in China.

Twenty-one in-depth interviews were conducted to identify each factor in the framework (Strauss \& Corbin, 1990). Such a framework can help both researchers and practitioners to understand more about the underlying factors that bidders use in choosing their bidding strategies. The framework also provides a guideline for future researchers in this line of research.

\section{Literature Review and proposal for a preliminary framework}

\section{Online Bidding Strategies}

A number of studies of online bidding strategies have used value, bidding time, and occurrence of bids as proxies to differentiate online bidding strategies. In 
reviewing the literature, we have identified five major types of bidders: (1) evaluators (early or middle), (2) participators, (3) agent bidders, (4) opportunists, and (5) "sip-anddippers" (Bapna, Goes, \& Gupta, 2000, 2001, 2003b; Bapna et al., 2004). By understanding the conceptual difference between these types of bidders, one can deduce their corresponding bidding strategies.

\section{Bidding Strategy of Evaluators: Jump Bidding}

Evaluators are bidders who usually bid only once, either during the early or middle stage of an auction (Bapna et al., 2004). They are termed such because they are believed to "evaluate" the product being auctioned through their sole bid. Evaluators usually bid higher than is necessary. They bid at a price that is higher than the current one, plus the minimal bid increment. Easley and Tenorio (2004) call this strategy jump bidding. It can provide an opportunity for some inexperienced bidders to evaluate a product's price, and is even occasionally adopted by experienced bidders (Borle, Boatwright, \& Kadane, 2006). Bidders can use this strategy to signal to their rivals that they have strong interest and bidding ability (Avery, 1998; Bapna et al., 2004; Robert F. Easley \& Tenorio, 2004). Although there may be several "jumps" in one auction, usually the first jump is greater than the others (Raviv, 2008), making the evaluator's jumping strategy more notable.

\section{Bidding Strategy of Participators: Ratchet Bidding/Nibbling}

Participators submit their bids by following the other bids and increasing the price by minimal bid increments ${ }^{1}$ (Bapna et al., 2004). They behave in this manner regardless of which stage the auctions are in. Participators' bidding strategy is called

\footnotetext{
${ }^{1}$ A minimal bid increment is the minimal amount of money the next bidder can add to the current price. For example, if the current price is $\$ 5$ and the minimal bid increment $\$ 2$ in one auction, the next bidder must bid at least $\$ 7$.
}

ratchet bidding (or nibbling), as each bid is increased by minimal bid increments (Brint, 2003; Chang, 2012; Friesner, Bozman, \& McPherson, 2008). This kind of bidding strategy is commonly used in both offline and online auctions. Friesner et al. (2008) explain that nibbling is a technique to deduce the auction value in online auctions when the value has a high level of uncertainty.

\section{Bidding Strategy of Agent Bidders: Agent Bidding}

Agent bidders are those who employ online bidding agents in submitting their bids (Bapna et al., 2004). A bidding agent actually is a form of automatic bidding software (usually embedded in online bidding systems) that can help a bidder to offer bids at the minimal level needed to outbid others. This series of bids will continue until the bid is raised to the bidder's desired pre-set maximum price. Some researchers highly recommend agent bidding due to its efficiency and competitive advantage over other bidders (Puro, Teich, Wallenius, \& Wallenius, 2011; Trevathan \& Read, 2011).

\section{Bidding Strategy of Opportunists: Snipe Bidding}

Opportunists are late bidders who wait until an auction is about to end before bidding (Bapna et al., 2004). By bidding only near the end of an auction, opportunists can avoid a price war and can outdo their rival bidders by leaving them no time to respond (Namazi \& Schadschneider, 2006). This approach by opportunistic late bidders is generally referred to as snipe bidding (Borle et al., 2006; Roth \& Ockenfels, 2002). Researchers have found that later bidders are more likely to win their auctions, and at a lower price (Gonul \& Leszczyc, 2011), and that snipe bidding is the most popular bidding strategy (Cui \& Lai, 2013).

\section{Bidding Strategy of "Sip-and-Dippers": Bid Early, Wait, then Snipe}

Finally, sip-and-dippers are those who bid in the early stage of an auction, wait in the 
middle stage, and then bid again near the end of the auction (Bapna et al., 2004). These bidders usually are seen in multi-unit auctions, which provide more than one unit of a product. As illustration, one seller provides 10 units of identical hats to be auctioned, which are priced starting from $\$ 10$, with the minimal bid increment of $\$ 5$. At the end of the auction, bidder $A$ bid at $\$ 30$ for 8 units. Bidder $B$ also bid at $\$ 30$ for 2 units and bidder $C$ bid at $\$ 35$ for 2 units. The final auction price will be the lowest winning price of $\$ 30$. Because $\mathrm{C}$ bid the highest, he/she can receive the first 2 units at $\$ 30$ (although he/she bid at \$35). Between $A$ and $B$, the one who entered earlier in the auction can received the time priority and be served first. If $A$ entered earlier in the auction, he/she can receive the remaining 8 units and $B$ will received nothing. If $B$ entered the auction earlier, he/she can receive 2 units, with only 6 units remaining for $A$. Therefore, bidders in multiunit auctions sometimes need to bid early to receive the time priority to outbid those who have submitted the same bidding price. This type of bidder actually adopts another variant of snipe bidding that involves one more bid during the early stage to keep time priority in multi-unit auctions.

\section{Antecedents of Bidding Strategies}

In this section, we start to build our framework by finding antecedents of bidding strategies found in our review of the literature. We categorize these antecedents in terms of bidding mechanisms, product categories, bidder characteristics, and bidder motivation.

\section{Bidding Mechanisms}

In this study, we define bidding mechanism as all the parameters, functions and protocols provided by sellers. In a study using the simulation method, Bapna et al. (2003b) found that an auction's starting prices and bid increments influence bidding strategies. Roth and Ockenfels (2002), meanwhile, found that the ending rules of online auctions influence the adoption of snipe bidding. In particular, the hard close (where the auction ends at a certain time) as compared to the soft close (where the auction ends if there are no more bids submitted) will see an increase in the use of snipe bidding, because sniping is more effective in hard-close auctions (Dang, Hu, \& Liu, 2015). According to Wintr (2008)'s study of eBay, late bidding is a strategic response to ratchet bidding: experts who desire to keep their willingness to pay privately usually bid late.

The specific environmental factors that we include in our framework include both website factors and auction environment factors. Online auction intermediaries provide online bidding agents, which is the technology most relevant to the online bidding environment. The effectiveness of the agents is associated with their application. Thus, according to the technology acceptance model, the more effective an online bidding agent is perceived to be, the more likely the agent will be deployed (Davis, 1989). This leads to increases in the adoption of the agent bidding strategy. In addition to online bidding agents, the perceived effectiveness of some technological services, such as a host site's feedback mechanisms and its escrow service, needs to be investigated. Primarily, Pavlou and Gefen (2004) have found that the effectiveness of feedback mechanisms and escrow services are important in the online marketplace. In other studies, researchers have found that reference price also affects online bidding behavior (Amyx \& Luehlfing, 2006; Kamins, Dreze, \& Folkes, 2004). Because search engines in online auctions can help consumers to compare product prices from different sellers, the effectiveness of different search engines will also be investigated in the framework.

Specific factors of the auction environment provided by the sellers include auction starting price, auction bid increments, and, in some websites, different ending rules. Researchers have found that bid increments do have some positive influence on active participation (Bapna et al., 2003b). Low bid 
increments will increase the auctioneer's revenue, but will reduce the revenue as it increases to a certain high level (Bapna et al., 2001; Bapna, Goes, \& Gupta, 2003a; Bapna et al., 2003b). Researchers have observed that the starting price has some influence on online bidding behavior, including what the final price will be, the number of bids entered, and access to the auction (Ariely \& Simonson, 2003; Brint, 2003; Gilkeson \& Reynolds, 2003; Mcdonald \& Slawson, 2002). We thus propose that these two factors-bid increment and starting price-likely affect the online bidders' bidding strategies.

An online auction's ending rule (hard close or soft close) is another factor that we found in the literature. Most studies found that hard-close auctions yield lower revenue compared to soft-close auctions, particularly when the item's value is low (Onur \& Tomak, 2006). A controlled field experiment, meanwhile, found that these ending rules can directly affect bidding strategy, since different ending rules will generate different degrees of the adoption of snipe-bidding (Ariely, Ockenfels, \& Roth, 2005).

The final environmental factor in auctions to be studied is provided by other bidders who are participating in a single auction. The bids by others may cause a "herding effect," wherein more bidders will bid when there have been more bids submitted or posted in online auctions (Ariely \& Simonson, 2003; Kauffman \& Wood, 2006; Ku, Malhotra, \& Murnighan, 2005; Stern \& Stafford, 2006). This herding effect will be further investigated in this research.

\section{Product Categories}

Researchers have also found that consumers exhibit different behaviors when buying different categories of products (Wilcox, 2000). Other researchers also found that different product categories would generate different levels of ratchetand snipe-bidding adoption (Borle et al., 2006). de Figueiredo (2000) characterized e-commerce products into four categories: commodity products (such as oil and paper clips), quasi-commodity products (such as books and compact discs), "look and feel" products (such as shoes and suits), and "look and feel" products with variable quality (such as art). To further simplify this classification system and to stress the effects of different bidding strategies, we chose two extremes for this classification in this study, commodities and collectibles, which have different levels of uniqueness as well as uncertainties in their true value. Friesner et al. (2008) explain that different product uniqueness and uncertainty of the product value in auctions will cause bidders to behave differently. Their study confirmed that products with a commonly known value will increase the occurrence of sniping. We therefore propose that bidding for commodities (such as clothes or decorative goods), or collectibles (such as artwork) can explain some of the differences in the bidding strategies adopted in online auctions.

\section{Bidder Consumer Behavior}

Beach and Mitchell (1978) found that individuals' personal characteristics, such as their knowledge, ability, and motivation, are important factors in determining which decision-making strategy or strategies they will employ. In our study, bidders were also heterogeneous, with various experiences and motivations in online auctions. We tried to determine which factors in bidders' consumer behavior may affect their bidding strategies. We categorize these in terms of bidder characteristics and bidding motivations, described below.

Bidder characteristics. Researchers have found that experience is one important factor related to strategic bidding (Borle et al., 2006; Wilcox, 2000) and auction-bidding success (Gilkeson \& Reynolds, 2003). One study found that bidder experience is negatively related to herd behavior (Friesner et al., 2008), while another study found that bidder experience is positively related to the use of sniping tools (Bapna, Jank, \& Shmueli, 2008). 
The bidders' characteristics in our study also include other important factors from the literature on online auctions. Risk aversion is identified as one of the bidders' preference among different types of auctions in the study by Ivanova-Stenzel and Salmon (2008) of. In addition, Bapna et al. (2004) discuss how a bidder's risk preference and value placed on time savings may influence his or her bidding strategies. We will investigate these two factors in our study, as well.

Bidding motivations. Researchers found that motivations play important roles in the decision-making process of the elaboration likelihood model of persuasion (Petty \& Cacioppo, 1986). Green and Swets (1966) also found that motivations had effects on judgment in the signal detection theory. Motivations are therefore crucial factors in decision-making, including the selection of an online bidding strategy. A bidding strategy selection is not only a decisionmaking process, but also a behavior that is usually driven by a number of motivations. Motivation factors therefore should be emphasized in the current research due to their importance in both the decision-making and motivation-behavior research areas.

The framework's motivational factors were drawn predominantly from the existing literature. Researchers have focused on hedonic motivation (Arnold \& Reynolds, 2003; Chiu, Wang, Fang, \& Huang, 2014; Lowry, Gaskin, Twyman, Hammer, \& Roberts, 2013) and utilitarian motivation (Babin, Darden, \& Griffin, 1994; Chiu et al., 2014; Kim, 2006; Lowry et al., 2013) as two major categories of motivations in online interactions. Researchers have found that joy, a form of hedonic motivation, is important in systems interactions (Lowry et al., 2013; Venkatesh, 1999). Other studies have found that consumers have two primary utilitarian motivations in online auctions: to obtain the auctioned item and to save money (Cameron \& Galloway, 2005). In addition to these two factors, saving time will also be investigated as a utilitarian motivation, because time is another form of cost in modern life (e.g., "time is money").

\section{Proposing a Preliminary Contingency Framework for Online Bidding Strategies}

Contingency theory argues that corporation management or decision-making is contingent upon both the internal and external situations of the company or the decision-making process (Luthans, 1973; Luthans \& Stewart, 1977). In our context, the selection of different bidding strategies in online auctions is a decision-making process. Again, if contingency theory holds in a bidding context, there is no universally appropriate bidding strategy that is applicable to all situations. The choice of online bidding strategies therefore is contingent upon external and internal factors. Therefore, this research aims to propose a contingency framework to offer a better understanding of the antecedents of bidding strategies in different contexts.

In the framework we developed based on our review of the previous literature, these factors are categorized into bidding mechanisms, product categories, and bidder consumer behavior, as indicated in Figure 1. The external environment is one of the early and important contextual factors that have been examined at the foundation of contingency-based research (AbdelKader \& Luther, 2008; Elgharbawy \& AbdelKader, 2013). In our study, bidding mechanisms, including website factors and auction factors, are the manifestation of environmental factors. In addition, for the internal factors, the choice of decision strategy is contingent upon the characteristics of the decision maker (e.g., knowledge, ability, motivation) and the characteristics of the decision task (e.g., complexity, ambiguity) (Kumar \& Subramaniam, 1997). In our study, the characteristics of the decision maker that we focused include bidding characteristics and motivation. Product categories can be viewed as a manifestation of the characteristics of the decision task (Solberg, 


\begin{tabular}{|l|l|l|}
\hline \multicolumn{1}{|c|}{ Antecedents } & \multicolumn{1}{|c|}{ Bidding Strategies } \\
\hline Bidding Mechanisms & & $\bullet$ Ratchet bidding \\
\hline \begin{tabular}{ll} 
Product Categories \\
\hline $\begin{array}{l}\text { Bidders' Consuming Behavior } \\
\text { Bidding Characteristics } \\
\text { Bidding Motivations }\end{array}$
\end{tabular} & $\bullet$ & $\bullet$ Agent bidding \\
\hline
\end{tabular}

Figure 1 - A Preliminary Contingency Framework for Online Bidding Strategies

\section{Research Methodology}

In order to explore the antecedents of online bidding strategies in the framework, we conducted in-depth semi-structured interviews that aimed to acquire rich and detailed information (Carson, Gilmore, Gronhaug, \& Perry, 2001) from online bidders. Semi-structured interviews help to investigate bidders' attitudes in greater depth. These types of interviews enabled us to seek both clarification and elaboration of the answers given to us, which led to a deeper understanding of the interviewees' selection of bidding strategies. We followed best practices for minimizing bias by predetermining our questions and basing them on our theoretical framework (Ghauri, Grønhaug, \& Kristianslund, 1995; Jayaratne \& Stewart, 1991). We generally asked these questions in an open-ended format, however, which provided the flexibility to facilitate variation in the questions we asked. This approach also gave respondents the freedom to answer as they desired (Frankfort-Nachmias \& Mias, 1996). This method also allowed us to probe beyond the answers given, to encourage respondents to give more detailed answers, to clarify answers, and to encourage interviewees to talk at length about their bidding patterns and antecedents relevant to this research. The questions used in this study were prepared according to the structure of the contingency framework (see the Appendix), based on the following categories: bidding strategies, bidding mechanisms, product categories, and bidders' consuming behavior. Finally, we asked demographybased questions, which we used to determine whether demographic factors might have influenced the interviewees' decision-making on bidding strategies.

\section{Sampling}

We used convenience sampling to recruit experienced online bidders in China. We included only the bidders who had been 
successful in bidding in at least ten separate auctions in the study. This purposeful sampling allowed us to avoid respondents who were amateurs or who had little experience in online bidding. The respondents therefore easily understood our questions and were able to describe the decision-making processes they used to choose bidding strategies during the interview. This can also guarantee that the respondents were familiar with online auctions and could easily understand bidding strategies and other concepts. This can also help to establish the validity and reliability of the measures used in this qualitative research. With experienced interviewees, we can collect data not only on their current bidding strategies, but also on their past bidding behavior, through which we examine the bidding strategy changes. Furthermore, it also allows us to receive more information spanning products and auctions because of their experience in the online auction world.

\section{Data Collection}

We conducted the semi-structured interview as follows. First, we invited an expert on qualitative interviews to examine and comment on the questions; a steering committee assisted in the design and administration of the interview protocol. Second, during the pilot test, we invited several bidders, separate from the interviewees of this research study, to check the questions to ensure that they were all understandable to professional Chinese online bidders. The authors made a few modifications based on the bidders' suggestions. We conducted a pilot communication between the interviewer and each interviewee candidate to ensure cooperation with the interviewers. This process also helped the two parties to build a good relationship, which enhances the credibility of an interview (Mitchell, 1983). We conducted one-hour online interviews with each interviewee. Again following Mitchell (1983), a single interviewer who was highly trained in this research methodology conducted all of the interviews in this study; this reduced the interviewees' bias that can result from inconsistencies in approach taken by different interviewers.

We conducted the interviews online, via text chatting. The interviewees especially appreciated this approach to interviewing because, as professional online bidders, this was their preferred means of communication in their daily work, and was something they were comfortable doing. This method had the added advantage of allowing us to record the content simultaneously while we conducted the interviews. The use of the chatting message history helps in reducing transcription errors.

\section{Data Analysis}

We analyzed the data via content analysis, using two steps. We used this approach to reduce information overload threats, which may negatively influence research quality because of the stimulus overload experienced by the researchers. We analyzed the primary content simultaneously with the data collection after each interview, as suggested by Mitchell (1983). Specifically, each interview was entirely transcribed and analyzed before conducting the next interview. We broke the data of each interview into discrete parts according to the contingency framework. To explore the effects of the antecedents on bidding strategy, we analyzed the data first vertically along each interview and then horizontally to allow comparison with each other. In addition, to properly analyze qualitative data from our semi-structured interviews, we followed leading methodological guidelines set out by Allen, Poteet, and Burroughs (1997) and Lee (1999), as follows: (1) inspect the transcript text and identify themes that are similar, then group them together; (2) name each group that represents themes within the group; (3) categorize the text, and then cross-check the categories with the second party and the authors of the paper, to increase reliability; (4) categorize the themes and match the text with the themes; (5) collapse the data across similar themes 
to reduce the number of themes; and (6) when the themes have been finalized, collapse or cluster the themes into meaningful and higher-order factors. As a result, we successfully conducted and analyzed a total of twenty-one interviews.

\section{Results}

This section initially reports the respondents' profiles in this study. We subsequently apply the content analysis and results to the contingency framework. We summarize and present the results in a table for each part. Based on these results, we then create a parsimonious model of online bidding strategy adoption.

\section{Respondent Profiles}

A total of 21 in-depth interviews were conducted. The sample comprised seven male and fourteen female respondents. All of the interviewed bidders had participated successfully in a minimum of ten auctions; most had participated in many more. Six of the 21 bidders (one third) had participated in more than one bidding website. The websites ranged from international websites such as Yahoo, eBay, and Amazon to Chinese sites such as Taobao ${ }^{2}$. Notably, some of these websites have both traditional fixed-pricing purchasing capabilities (e.g., one may purchase books online at a fixed price, without bidding) and dynamic-pricing auctions; our research focused only on dynamic-pricing auctions. Table 1 summarizes our respondents' profiles.

\section{Table 1 - Profiles of Professional Online Bidders from the Interviews}

\begin{tabular}{|c|c|c|c|}
\hline Interviewee ID & Gender & Successful auctions & Auction website(s) \\
\hline 1 & $\mathrm{~F}$ & $50-100$ & Taobao and Yahoo \\
\hline 2 & $\mathrm{M}$ & $50-100$ & eBay and Yahoo \\
\hline 3 & $\mathrm{~F}$ & $10-20$ & Taobao \\
\hline 4 & $\mathrm{~F}$ & $20-50$ & Taobao \\
\hline 5 & $\mathrm{M}$ & $20-50$ & eBay and Taobao \\
\hline 6 & $\mathrm{~F}$ & $>100$ & eBay and Taobao \\
\hline 7 & $\mathrm{~F}$ & $20-50$ & Amazon, eBay, and Taobao \\
\hline 8 & $\mathrm{~F}$ & $>100$ & Taobao \\
\hline 9 & $\mathrm{~F}$ & $50-100$ & Taobao \\
\hline 10 & $\mathrm{~F}$ & $10-20$ & Taobao \\
\hline 11 & $\mathrm{M}$ & $>100$ & Taobao \\
\hline 12 & $\mathrm{~F}$ & $>100$ & Taobao \\
\hline 13 & $\mathrm{M}$ & $>100$ & Taobao \\
\hline 14 & $\mathrm{~F}$ & $50-100$ & eBay, Taobao and Yahoo \\
\hline 15 & $\mathrm{~F}$ & $>100$ & Taobao \\
\hline 16 & $\mathrm{M}$ & $20-50$ & Taobao \\
\hline 17 & $\mathrm{~F}$ & $20-50$ & eBay and Taobao \\
\hline 18 & $\mathrm{M}$ & $20-50$ & Taobao \\
\hline 19 & $\mathrm{~F}$ & $20-50$ & Taobao \\
\hline 20 & $\mathrm{~F}$ & $10-20$ & Taobao \\
\hline 21 & $\mathrm{M}$ & $50-100$ & Taobao \\
\hline
\end{tabular}

2 Taobao.com is a domestic website in China that has developed dramatically in recent years; it has become the biggest electronic marketplace in mainland China. In addition to providing numerous fixed-pricing products, Taobao.com is also the most popular auction site among the aforementioned websites: all twenty-one of the interviewees had used it. 


\section{Content Analysis and Results}

\section{Taxonomy of Bidding Strategies}

The research results of this study confirmed the taxonomy of bidding strategies that was identified in the review of the literature. We confirmed that the interviewees adopted the jump, ratchet, agent, snipe, and sip-and-dip bidding strategies at least once when bidding. Table 2 summarizes the results of the content analysis of bidding strategies. Meanwhile, we found a number of significant findings that differed from previous research. First, the "earlier evaluators" found in Bapna et al. (2004) was not considered a viable strategy in our sample. Interviewees 2 and 20, respectively, said that this strategy was "an ineffective way" that "can only raise auction price quickly." We believe this inconsistency can be explained by the fact that most of the auctions in Taobao are single-item auctions in which bidders do not have to get priorities with early bids as do in Yankee auctions (Bapna et al., 2004). Importantly, Bapna et al. (2004) noted that evaluators have largely moved from the early stage of auctions to the middle stage, owing to the so-called learning effect, which echoes the concerns raised by our interviewees. In fact, some interviewees (such as Interviewees 1, 9, and 21) did recall that they had bid in this manner when they were just starting out, but abandoned the strategy when they became more experienced and successful in online bidding.

\section{Table 2 - Summarized Results of Bidding Strategy Taxonomy}

\begin{tabular}{|l|l|}
\hline Bidding Strategy & $\begin{array}{l}\text { Results; Confirmed as per previous research but with new information } \\
\text { stemming from our research: }\end{array}$ \\
\hline Jump bidding & $\begin{array}{l}\text { - Usually does not occur in the early stage of bidding } \\
\text { - May occur in the middle stage of multi-item auctions } \\
\text { - Combined with agent bidding in some single-item auctions } \\
\text { - Combined with snipe bidding to make the latter more effective }\end{array}$ \\
\hline Ratchet bidding & - Confirmed as noted in previous research \\
\hline Agent bidding & $\begin{array}{l}\text { - Confirmed as noted in previous research } \\
\text { - Occasionally combined with jump bidding to form "jump-agent" bidding }\end{array}$ \\
\hline Snipe bidding & $\begin{array}{l}\text { - Confirmed as noted in previous research } \\
\text { - Occasionally combined with snipe bidding to form "jump-snipe" bidding }\end{array}$ \\
\hline Sip-and-dip bidding & - Confirmed as noted in previous research \\
\hline
\end{tabular}

Second, we observed jump bidding in our study. Jump bidding was shown in multi-unit auctions as well as in single-unit auctions. In multi-unit auctions, bidders can adopt jump bidding directly, such as the case of Interviewee 14, who bids at a higher price than necessary to make a jump that can send other bidders the signal that "I am determined to obtain some of these items." This is usually done because the bidder may not have to pay the price that he or she submits (i.e., the final price of multi-item auctions will be the lowest winning bid at the end). The possible lower final price makes the "jumping" behavior less risky, which encourages some bidders to "jump" to send their signals to the other bidders, mostly during the middle stage of the auction.

This is usually done because the bidder may not have to pay the price that he or she submits (i.e., the final price of multi-item auctions will be the lowest winning bid at the end). The possible lower final price makes the "jumping" behavior less risky, which encourages some bidders to "jump" to send their signals to the other bidders, mostly during the middle stage of the auction.

Interestingly, a new form of "jump" is used in single-unit auctions due to different bidding systems. For instance, single-unit auctions in Taobao.com will automatically trigger a bidding agent when a bidder jumps 
unusually high (by several times the minimal bid increment) over the current price. In this case, the current price will not be raised to the actual bid, but only by a minimal bid increment until the other bidders respond. The bidding agent automatically outbids the other bidders until other bidders cease to compete or the current price has been gradually increased higher than the bidder's actual bid. This mechanism originally was implemented on Taobao.com to protect bidders from paying too much. Interviewee 2 described this new form of "jump" as "a more effective method" than traditional "jumps" in three ways: (1) it keeps the previous signaling function from "jumping," because their bids will be marked with "agent bids" in the bidding list when the bidding agent is triggered; this will tell others that "my will to get the item is strong"; (2) the actual bids are concealed by bidding systems and are hard to guess, which can eventually frighten away other bidders; and (3) the bidder who jumps may not have to pay his or her reservation price if others stop competing before the price is achieved, which helps the winning bidder to gain some consumer surplus (i.e., the amount a bidder is said to be willing to pay more than the amount the bidder actually pays). Because the jump-bidding strategy in single-unit auctions is combined with agent bidding, we call it "jump-agent bidding." In addition to this combination of jump and agent bidding, we likewise discovered a jump-snipe bidding variant.

Although the interviewees deemed pure snipe bidding to be an effective strategy, a sniper may still face sniping from others. When several bidders choose this strategy in the same auction, only one person who is skilled and lucky enough can snipe successfully. He or she has to submit a bid earlier than others to ensure the bid is available, but late enough to keep others from responding. If this happens, other snipers may eventually lose the auctioned item, even though they have waited for a long time for it. In this case, bidders learn to snipe with a higher submitted bid in order to ensure that they can obtain the item. Here, a higher bid will help defeat the others' snipes even if the higher bid's timing is not optimal. This strategy does not aim to signal to other bidders a strong will to win, but rather the interesting twist "to beat other snipers within a limited time." The mixed strategy not only allows bidders to outbid their rival bidders with unexpected bids but also leaves no chance for rivals to catch up in time with the big jump. Therefore, Interviewee 2 considers the mixed strategy of snipe-jump "much more effective" than standard sniping.

From our analysis, we can see that, with the exception of jump bidding by early evaluators, which our interviewees found to be a poor strategy for winning, the basic strategies discussed in the previous literature were still validated as actual strategies used by professional online bidders. We also showed that some variants or combinations of these bidding strategies may appear. A reason for this new phenomenon can be explained from the strategies themselves, which are essentially compatible; they are not independent or exclusive from each other. Another reason that triggered the variants or combinations was determined by real bidding systems provided by the different online auction intermediaries. For instance, the emergence of the jump-agent bidding in Taobao's single-unit auctions is determined by its online bidding system. The true bidding strategy selection of the bidders therefore will be affected depending on how the mechanism is designed in other online auction systems.

\section{Bidding Mechanisms}

Technological service effectiveness was the first factor among the environmental factors that we investigated. When the interviewees were asked about the effectiveness of the bidding agent in online auction websites, most perceived the agent as being important to some extent. Among those who adopted the agent bidding strategy, they perceived that the bidding agent they used 
was effective. A respondent said that "it cannot only help me to bid but also help me to fulfill the motivation to save time." Here, the agent can automatically submit bids step-by-step when bidders do not have time to check auctions, or if they are offline. They can submit bids in this way as if they were consistently participating in the auctions, but without spending as much time. In effect, most bidders tend to adopt agent bidding more if they feel that "the service functions well."

In addition to the bidding agent, another technological service that the interviewees favored is called "watch-the-item" (WTI, or "favorite items" in some websites). Nearly half of the respondents (10 out of 21 interviewees) considered it a "helpful assistant" provided by auction sites to help bidders track the auctions that they may want to participate in later. The effectiveness of this service enhances the occurrence of snipe bidding because bidders can now check their favorite auctions at any time and snipe those auctions that are coming to an end. The effectiveness of auction-related technologies therefore will persuade bidders to adopt them and choose the related bidding strategies.

The effectiveness of some technological services, however, did not show such influence on bidding strategies. On the one hand, all interviewees noted the importance of feedback mechanisms. They believed that these mechanisms could help them to evaluate the sellers and to make a decision about whether or not to enter an auction. All of the informants expressed the opinion that this mechanism could not affect bidding behavior once the entry decision had been made. A search engine could help bidders to set their own reservation prices, but it likewise did not affect their bidding strategies during the online bidding process.

This was also true for payment channels. The interviewees considered escrow services (or third party services, such as payment or delivery) to be important in an online exchange, although the services did not generally influence bidding strategy. Interviewee 1 said that she had to conduct a face-to-face trade after the online bidding because Yahoo.com.hk did not provide an escrow service. Despite its effects on the post-bidding trade format, the existence of payment channels still had no effect on the bidding behavior, according to the experience of all twenty-one informants.

Another important environmental factor confirmed by our study is the social presence of other bidders. The number of other bidders at the auction may also affect bidding behavior, lead to a herding bias and have a negative effect which implies higher winner's curse (Rafaeli \& Noy, 2005). For instance, eighteen out of the twenty-one interviewees reported evidence of the herding effect, although to varying degrees. Some interviewees said that when there were more bids showing in an auction, their behavior may change and they might be ready to pay more to obtain the item. Over time, this behavior will increase their reservation price, meaning that the final price may also be raised accordingly. The herding effect may also change their motivations for bidding. Under this effect, they are more motivated to win the bid and obtain the item. One interviewee said, "Now the important issue is not the price, but the item." Some interviewees $(7,13,16$, and 19) even admitted that they had participated in "price wars" with other bidders at least once. These interviewees also expressed excitement in being involved in an auction in which there were more bids, especially when "there are one or more bidders who always bid right after you." Interviewee 7 said, "Fighting with them is fun and exciting." The emphasis in this situation evidently is not on the item auctioned but in the excitement of competition. Several interviewees also described winning an auction as a satisfying feeling of "defeating" other rivals. The professional bidders also adopted ratchet bidding, or "nibbling," when the herding effect occurred, because they wanted to participate in the competition 
personally. In addition, according to social influence theory (Latane; Rafaeli \& Noy, 2005), individuals may treat others as referents to compare behaviors, attitudes and performance. Bidders present at an auction are influenced by one another. They may refer to the estimations of other bidders to make accurate decisions because items sold in auctions sometimes do not have a definite market value. Thus, the presence of other bidders could exert an influence on the individual's valuation and bidding behavior.

The herding effect, however, was less common in commodity auctions than in collectible auctions. In commodity auctions, bidders sometimes set a fixed reservation price for the commodity. Some were more cautious when there were more bids showing up for a commodity because more bids could increase the final price of the auction (Du, Hom, Yu, Fang, \& Wang, 2012). In order to avoid the "winner's curse" (Easley, Wood, \& Barkataki, 2011), in which the winning bidder may pay more than the object is worth, bidders either set a reservation price to the bidding agent or sniped at the end of the auction.

Because 13 interviewees said that bid increments influenced their bidding behavior, we found that bid increments may be relevant to the bidding strategies adopted in the auction environment. If the bid increment in a given auction was large-for instance, more than that of similar auctions-they carefully followed the auction by ratchet-bidding because of the high risk brought about by a large bid increment. They did this rather than jumping to a high price despite the moderation of bidding agents. When the bid increment was small, on the other hand, bidders tended to set a high price to the bidding agent, and had it to compete for them.

The influence of the starting price on bidding strategies remains unclear, because most of the auctions the interviewees participated in had a standard starting price (for example, the "one-dollar-start-auction" on Taobao.com). Most of the interviewees were more concerned with the current price, and they did not usually act during the early period of an auction (except for early bids for time priority in multi-unit auctions). They also believed that if the starting price of an auction was very low, others would raise it through the natural course of bidding. In contrast, when the starting price was too high, the bidders often considered not participating. The influence of the starting price directly on the bidding strategy choice therefore is not apparent.

One interviewee who participated in Yahoo.com auctions, however, identified the effect of ending rules as being important. Yahoo.com is the only auction website that provides two optional auction-ending rules to sellers. The interviewee confirmed that hard-close ending rules will definitely enhance the chances of snipe bidding. The effect of this environmental factor needs further confirmation, however, because only one interviewee reported this phenomenon. We term this type of effect as a marginal effect that was only observed by a few interviewees. Table 3 summarizes the results of the environmental factors. 


\begin{tabular}{|l|l|}
\hline Table 3 - Summarized Results of Bidding Mechanisms \\
\hline Bidding Mechanisms & Results \\
\hline Effectiveness of bidding agent & - Confirmed to have an effect on agent bidding \\
\hline Effectiveness of "watch-the-item" (WTI) & • Discovered to have an effect on snipe bidding \\
\hline Effectiveness of escrow services & - Cannot be confirmed to have an effect on bidding strategies \\
\hline Effectiveness of feedback mechanisms & - Cannot be confirmed to have an effect on bidding strategies \\
\hline Effectiveness of search engines & - Cannot be confirmed to have an effect on bidding strategies \\
\hline Herding effect & $\begin{array}{l}\text { - Confirmed as per previous research } \\
\text { - Motivates bidders to obtain the item (collectibles) } \\
\text { - Motivates bidders to adopt ratchet bidding } \\
\text { - Has less effect in commodity auctions }\end{array}$ \\
\hline Bid increment & $\begin{array}{l}\text { - Confirmed to have an effect on bidding strategies } \\
\text { - High bid increments will lead to ratchet bidding }\end{array}$ \\
\hline Starting price & - Low bid increments will increase jump-agent bidding \\
\hline Ending rules & Cannot be confirmed to have an effect on bidding strategies \\
\hline
\end{tabular}

\section{Product Categories}

The interviewees perceived that there were a few differences between the auctions of different products, particularly for collectibles and commodities. They also proposed three dimensions to differentiate this classification: attractiveness, uniqueness, and availability. Bidders often bid for collectibles because they are attractive, unique, or are not easy to obtain in the markets (or all three). Examples of these are antiques or t-shirts of certain celebrities. The interviewees mentioned that they were highly motivated to obtain items because of these three factors. They also felt more excited when they won these auctions and acquired the items. As a result, they usually applied ratchet bidding to evaluate the true value of the collectibles, and snipe-jump bidding to obtain the items.

Nevertheless, bidders who bid mainly for commodities, such as clothes or decorative items, reported that those items were less attractive or unique and were highly available in online markets. They were therefore more motivated to save money than to obtain the actual items themselves. Because of this, setting a low fixed reservation price to the bidding agent, or sniping at the end of certain auctions, are the two main strategies used in this case. It therefore appears that the type of product involved in an auction strongly influences both bidding motivations and strategies used.

Interestingly, bidding for either brand-new or second-hand products did not appear to influence interviewees' bidding motivations or strategies. All of the interviewees concurred that what really mattered was whether the product was a commodity or a collectible. It did not matter whether it was new or used. Table 4 summarizes the results for product categories.

\section{Table 4 - Summarized Results of Product Categories}

\begin{tabular}{|l|l|}
\hline Product Categories & Results \\
\hline Commodities & $\begin{array}{l}\text { - Confirmed to be different from bidding on collectibles } \\
\text { - Motivated bidders to save money, not to obtain the item }\end{array}$ \\
\hline Collectibles & $\begin{array}{l}\text { - Confirmed to be different from bidding on commodities } \\
\text { - Motivated bidders to obtain the items, followed by to save money }\end{array}$ \\
\hline New item & - not observed to be different from bidding on used item \\
\hline Used item & - not observed to be different from bidding on new item \\
\hline
\end{tabular}




\section{Bidder Characteristics}

Bidding experience was the first relevant bidder characteristic we identified that influences bidding strategy. In fact, eleven out of twenty-one interviewees (Interviewees 1, 6, 8, 9, 11, 14, 15, 18, 19, 20 , and 21 ) directly reported the changes in bidding strategy adoption while they accumulated experience. Interestingly, almost all of these interviewees used ratchet bidding during the early stages in their bidding careers. Interviewee 17's reason was that "it is enjoyable to bid by myself." The adoption of this strategy, however, decreased with time. They subsequently learned to bid either by employing agents or by bidding near an auction's end, and they considered the agent or snipe bidding as a "more mature or effective method." This phenomenon is consistent with the research findings of previous studies. For example, Ariely et al. (2005) found that bidders use ratchet bidding less as they gain experience. Bapna et al. (2004) found that bidders gradually learned to use bidding agents as this new technology became available. Borle et al. (2006) found that some experienced bidders tend to bid late. All of these can be explained by Rieskamp and Otto (2006) strategy selection learning (SSL) theory, which states that the strategy selection process is based on reinforcement learning.

Six interviewees did not report changes as they accumulated experience, however. When the data were examined carefully, we found that five of these six interviewees started bidding by using bidding agents and had not changed their methods since then. The remaining sixth interviewees, who reported no changes from ratchet bidding, only had eleven winning bidding experiences. We therefore surmise that this respondent is still in the process of learning and his experience may not have been strong enough to cause changes in his bidding strategy. In summary, we confirmed the impact of bidding experience on the bidders' bidding strategies. The less experience the bidders had, the more they tended to enjoy the bidding process itself, and the less they tended to select agent- or snipe bidding as a bidding strategy.

In addition to bidding experience, we also observed that the time a bidder had available to be online had a strong influence on bidding behavior. People naturally have different time availabilities and thus different bidding strategies. The interviewees who claimed to be busy and had less time to spend online usually adopted an agentbidding strategy. A total of 7 interviewees reported that they did so because they did not have enough time to follow auctions; sometimes they could not even snipe an auction since they were busy doing other things. In contrast, some bidders (such as Interviewees 7, 14, and 17) who said they disliked agent bidding actually had high online time availability. These research findings confirm the conjecture of Bapna et al. (2004) about the influence of time availability on bidding strategies.

Bapna et al. (2004) also speculated that risk preference is an important factor in bidding behavior. We found it to have a marginal effect on bidding strategies in this study, however. Although risk preference had no direct influence on bidding strategies, bidders' risk preferences did have some influence on their reactions to other bidders. Those who were inclined to be highly stimulated by the other bidders' competition stated that they were "risk-seeking" or "sometimes risk-seeking, sometimes riskaverse." Those who were seldom affected by others reported that they were "riskaverse." In discussing this issue, some interviewees reported another bidder characteristic that may also contribute to this effect: we label this characteristic as "rationality" and found it to be related to the herding effect. The more rational the bidder was, the less he or she was affected by other bidders, and vice versa. That is, the least rational bidders were most likely to be influenced by the herding effect. We therefore established the bidders' rationality as a fourth bidder characteristic that has influence on bidding strategy selection, 
albeit indirectly. Table 5 summarizes the results of the bidder characteristics.

\begin{tabular}{|l|l|}
\hline \multicolumn{2}{|l|}{ Table $\mathbf{5}$ - Summarized Results of Bidder Characteristics } \\
\hline Bidder Characteristics & Results \\
\hline Bidding experience & $\begin{array}{l}\text { - Confirmed its effects on bidding motivations and bidding strategies } \\
\text { - Less experience leads to hedonic motivation and ratchet bidding } \\
\text { - More experience leads to snipe bidding or agent bidding }\end{array}$ \\
\hline Time availability & $\begin{array}{l}\text { - Confirmed its effects on bidding strategies } \\
\text { - Less available time leads to agent bidding }\end{array}$ \\
\hline Risk preference & - Confirmed its effects on the herding effect and bidding strategies \\
\hline Rationality & - Discovered to have an effect on the herding effect, then to bidding strategies \\
\hline
\end{tabular}

\section{Motivational Effect}

Motivations have long been found to influences judgment and choice processes (Einhorn \& Hogarth, 1981). All of the interviewees clearly stated their motivations in bidding. Overall, aiming at getting the product with minimal cost (saving money was called for short below) was the most popular bidding motivation we found. All of the interviewees explicitly expressed their motivation to save money in online auctions, which indicates its prominence in online auctions. Snipe bidding was mostly reported when bidders wanted to save money, because they believed it could help them avoid a price war by helping to keep the current price as low as possible. Motivated by saving money, bidders usually did not adopt explicit jump bidding because it may raise the final price quickly. Some bidders, however, tended to use agent bidding by submitting a reservation price to the agent with behavior similar to that of jump-agent bidding. The main purpose here was not to "jump," but rather to use the agent to control his or her bids and to avoid irrational bidding and thus save money. Interviewees also reported using ratchet bidding, but its preference among bidders with moneysaving motivations is not clear. Some interviewees, however, still reported that saving time influences their bidding strategies. They believed that agent- and snipe bidding saved time because bidders did not have to sit through the entire process of an auction.
The second popular bidding motivation was the acquisition of the item being auctioned. This usually happened when an item, often a collectible, was unique or difficult to purchase on the market. In this case, interviewees adopted the snipe-jump strategy as the most effective way to win auctions and to obtain the items. This occurred particularly in highly competitive auctions.

The third motivation was the hedonic motivation of online bidding - the enjoyment of the experience for its own sake. Most respondents thought that the online bidding process was enjoyable, especially when they were just learning how to bid. At this point in their learning, they would bid continuously by themselves, because they felt that ratchet bidding was enjoyable; this enthusiasm tended to wane over time, however. Some bidders who enjoyed the bidding process simply chose ratchet bidding for fun. In addition, some bidders mentioned the excitement that sniping brought to the end of an auction.

The online bidding motivation results are summarized in Table 6 , in which interviewees confirmed that saving money, obtaining an item, and enjoying the auction process each were highly influential on bidding strategies, while saving time was only marginally influential. We did not observe any other bidding motivations. 


\begin{tabular}{|l|l|}
\hline \multicolumn{2}{|l|}{ Table 6 - Summarized Results of Online Bidding Motivations } \\
\hline Bidding Motivations & Results \\
\hline Money-savings & $\begin{array}{l}\text { - Confirmed as the most popular motivation for bidding } \\
\text { - Leads most often to snipe bidding, followed by agent- and ratchet bidding }\end{array}$ \\
\hline Item-owning & $\begin{array}{l}\text { - Confirmed as the second-most popular motivation for bidding } \\
\text { - Usually occurs in auctions for collectibles } \\
\text { - Leads most often to snipe-jump bidding }\end{array}$ \\
\hline Hedonic motivation & $\begin{array}{l}\text { - Confirmed as the third-most popular motivation for bidding } \\
\text { - Especially popular when bidders are learning to bid } \\
\text { - Leads most often to ratchet bidding, followed by snipe bidding }\end{array}$ \\
\hline Time-savings & $\begin{array}{l}\text { - Marginally confirmed as a motivation in online auctions } \\
\text { - Leads most often to agent bidding, followed by snipe bidding }\end{array}$ \\
\hline
\end{tabular}

\section{Discussion and Future Directions}

Consistent with the contingency framework proposed in Figure 1, all data collected in the interview can be classified into the five parts in the framework. Moreover, our study examined the specific factors within the framework and identified the antecedents of online bidding strategy adoption. First, we partially confirmed basic bidding strategies in the extant literature, and saw the appearance of some new or variant bidding strategies. Second, we found that the effectiveness of bidding agents and WTI functions, the herding effect, auction bid increments, and ending rules all had a direct effect (an effect that was confirmed by the majority of the interviewees) on the bidding strategies. Third, bidding for commodities or collectibles will generate different bidding motivations and strategies in online auctions. Fourth, we found that experience in the bidding process directly impacts bidding strategies. Time availability is highly related to the adoption of the agent bidding strategy, whereas we found that risk preference and rationality influenced the herding effect. Finally, interviewees reported that the motivations to save money, to obtain an item, to enjoy oneself, and to save time were the direct drivers of online bidding strategies. The confirmed results are summarized in Table 7. Based on these results, Figure 2 depicts the confirmed research model that we propose for research and practice going forward.

\begin{tabular}{|c|c|c|c|c|}
\hline $\begin{array}{c}\text { Strategy } \\
\text { conditions }\end{array}$ & Ratchet bidding & Agent bidding & $\begin{array}{c}\text { Jump-agent } \\
\text { bidding }\end{array}$ & Snipe bidding \\
\hline $\begin{array}{c}\text { Bidding } \\
\text { mechanisms }\end{array}$ & $\begin{array}{l}\text { Herd effect }(+) \\
\text { Bid increment }(+)\end{array}$ & $\begin{array}{l}\text { Effectiveness of } \\
\text { bidding agent }(+)\end{array}$ & Bid increment (-) & $\begin{array}{c}\text { Effectiveness of "WTI" } \\
(+) \\
\text { Hard-close }(+)\end{array}$ \\
\hline $\begin{array}{l}\text { Product } \\
\text { categories }\end{array}$ & NA & NA & $\begin{array}{l}\text { Collectibles through } \\
\text { item-owning } \\
\text { motivation }(+)\end{array}$ & $\begin{array}{c}\text { Commodities though } \\
\text { money-saving motivation } \\
(+)\end{array}$ \\
\hline $\begin{array}{c}\text { Bidder } \\
\text { characteristics }\end{array}$ & $\begin{array}{l}\text { Bidding experience (-) } \\
\text { Risk taking through } \\
\text { herd effect (+) } \\
\text { Rationality through } \\
\text { herd effect (-) }\end{array}$ & $\begin{array}{l}\text { Bidding experience } \\
(+) \\
\text { Time availability (-) }\end{array}$ & NA & Bidding experience $(+)$ \\
\hline $\begin{array}{l}\text { Bidding } \\
\text { motivations }\end{array}$ & $\begin{array}{l}\text { Money-saving (-) } \\
\text { Hedonic motivation } \\
(+)\end{array}$ & Time-saving $(+)$ & Item-owning $(+)$ & $\begin{array}{l}\text { Money-saving }(+) \\
\text { Hedonic motivation }(+) \\
\text { Time-saving }(+)\end{array}$ \\
\hline
\end{tabular}




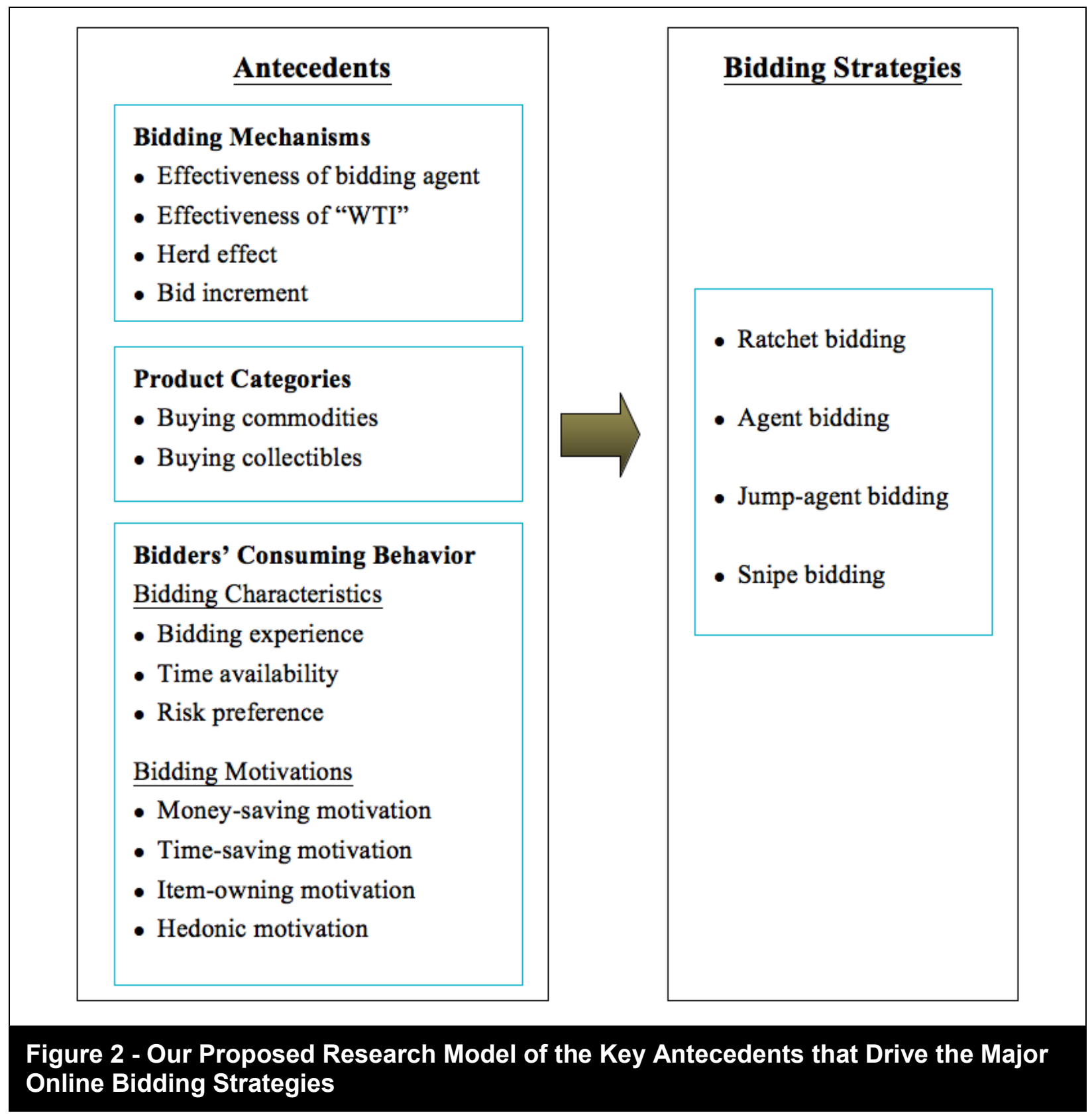

The significant contributions of this study was developing a contingency model of the online bidding strategies with environmental factors, bidding tasks, bidders' characteristics, and bidders' bidding motivations as the antecedents. This research is a pioneering effort in the comprehensive study of the antecedents of online bidding strategies. We have introduced the contingency theory to online auction research and incorporated motivations, both for the first time. We believe that the theoretical exploration in this study will assist in the solid development of online auction research. The research model of online bidding strategies explored in this study also provides researchers with a clear picture of the underlying reasons for the online bidders' heterogeneity. We likewise anticipate that the enriched knowledge will 
help researchers to advance the research in this area.

First, this study found that online bidding strategies are highly affected by online bidding systems provided by different auction sites. For instance, Taobao.com provides a novel yet user-friendly "bidding agent" that can be triggered automatically when the bid is unusually high. This bidding agent not only gained a high reputation among bidders, it also generated a new bidding strategy, known as "jump-agent" bidding. In addition, the effectiveness of technological services is also highly related to their adoption, which influences the entire world of online bidding. Future studies therefore can be conducted to design new online bidding tools to attract more bidders. Increasing the technological services will help website owners to leverage the information technology usage in online auctions. We expect to see more agent bidding, or hybrid bidding strategies that includes agent bidding, in the future.

Second, the interviews showed that the most popular bidding motivation in online auctions is to save money, followed by the motivation to own items and hedonic motivation. Auction website owners may refer to this order of motivations when designing a new system or developing technological services to meet consumers' needs more effectively. Future researchers can also further investigate the relationship between these bidding motivations and bidding strategies, this time with large sample-size survey methods to generalize the research findings in this study.

Third, this study showed that commodity auctions and collectible auctions bring different motivations for bidders that will eventually affect their bidding strategies. Websites should therefore consider developing two different bidding systems for these two kinds of bidding sectors. The segmentation of the products will enhance the efficiency of searching, comparing, and bidding. Future researchers can conduct rigorous research to determine the relationship of the biding strategies and the "winner's curse" of different products. The consumer surplus of these two different products can also be further examined.

Lastly, the results pertaining to bidder characteristics may provide practitioners with insights for their customized service. This can enable different services to be provided for different bidders based on their different characteristics. For example, different promotions are offered to bidders with different levels of experience. Inexperienced bidders can be encouraged to use bidding agents more often. Those who are busy, with a low level of time availability, can be provided with more efficient ways to bid. Risky products (such as loans) will be promoted more to risktaking bidders rather than to risk-averse bidders. The research findings can help the owners of auction websites to increase their user satisfaction.

Despite these contributions, this research remains an exploratory study. Further investigations are necessary on online bidding strategy research. Our respondents were professional online bidders in China; thus, it is possible that cultural factors may have influenced the results. This could be especially true in terms of bidders' motivations and decision-making strategies, as substantial systems research shows that cultural differences can influence motivations and decision-making in systems-use contexts involving interpersonal interaction (Lowry, Cao, \& Everard, 2011; Lowry, Zhang, Zhou, \& Fu, 2010; Posey, Lowry, Roberts, \& Ellis, 2010). Little is known if culture actually matters in online bidding decisions. Future research therefore needs to further confirm and build on our model in other cultural settings, such as in the United States and Europe. Due to the sampling frame and small sample size, that majority of interviewees had only participated in the TaoBao platform. Consequently, we could not to explore differences between different transaction platforms such as TaoBao, eBay, and Amazon. Future research should be 
conducted to examine if the differences among these platforms would impact consumers' bidding strategies. Some marginal effects that cannot be confirmed entirely in this study would still require additional investigations. Finally, measurements for each specific factor should be developed; we suggest a survey to collect mass data for statistical analysis as a triangulation to enrich and cross-check the data collected.

\section{References}

Abdel-Kader, M., \& Luther, R. (2008). The Impact of Firm Characteristics on Management Accounting Practices: A UK-Based Empirical Analysis. British Accounting Review, 40(2-27).

Allen, T.D., Poteet, M.L., \& Burroughs, S.M. (1997). The Mentor's Perspective: A Qualitative Inquiry and Future Research Agenda. Journal of Vocational Behaviour, 51, 70-89.

Amyx, D. A., \& Luehlfing, M. S. (2006). Winner's Curse and Parallel Sales Channels- Online Auctions Linked within E-tail Websites. Information \& Management, 43(8), 919-927.

Ariely, D., Ockenfels, A., \& Roth, A. E. (2005). An Experimental Analysis of Ending Rules in Internet Auctions. The Rand Journal of Economics, 36(4), 890-907.

Ariely, D., \& Simonson, I. (2003). Buying, Bidding, Playing, or Competing? Value Assessment and Decision Dynamics in Online Auctions. Journal of Consumer Psychology, 13(1), 113123.

Arnold, M. J., \& Reynolds, K. E. (2003). Hedonic Shopping Motivations. Journal of Retailing, 79(2), 77-95.

Avery, C. (1998). Strategic Jump Bidding in English Auctions. Review of Economic Studies, 65(2), 185-210.
Babin, B. J., Darden, W. R., \& Griffin, M. (1994). Work and/or Fun: Measuring Hedonic and Utilitarian Shopping Value. Journal of Consumer Research, 20(4), 644-656.

Bapna, R., Goes, P., \& Gupta, A. (2000). A Theoretical and Empirical Investigation of Multi-item On-line Auctions. Information Technology and Management, 1(1-2), 1-23.

Bapna, R., Goes, P., \& Gupta, A. (2001). Insights and Analyses of Online Auctions. Communications of the ACM, 44(11), 42-50.

Bapna, R., Goes, P., \& Gupta, A. (2003a). Analysis and Design of Business-toConsumer Online Auctions. Management Science, 49(1), 85-101.

Bapna, R., Goes, P., \& Gupta, A. (2003b). Replicating Online Yankee Auctions to Analyze Auctioneers' and Bidders' Strategies. Information Systems Research, 14(3), 244-268.

Bapna, R., Goes, P., Gupta, A., \& Jin, Y. (2004). User Heterogeneity and its Impact on Electronic Auction Market Design: An Empirical Exploration. MIS Quarterly, 28(1), 21-43.

Bapna, R., Jank, W., \& Shmueli, G. (2008). Consumer Surplus in Online Auctions. Information Systems Research, 19(4), 400-416.

Beach, L. R., \& Mitchell, T. R. (1978). A Contingency Model for the Selection of Decision Strategies. Academy of Management Review, 3(3), 439-449.

Borle, S., Boatwright, P., \& Kadane, J. B. (2006). The Timing of Bid Placement and Extent of Multiple Bidding: An Empirical Investigation Using eBay Online Auction. Statistical Science, 21(2), 194-205.

Brint, A. T. (2003). Investigating Buyer and Seller Strategies in Online Auction. Journal of the Operational Research Society, 54(11), 1177-1188. 
Cameron, D. D., \& Galloway, A. (2005). Consumer Motivations and Concerns in Online Auctions: An Exploratory Study. International Journal of Consumer Studies, 29(3), 181-192.

Carson, D., Gilmore, A., Gronhaug, K., \& Perry, C. (2001). Qualitative Research in Marketing. London: Sage.

Chan, R. Y. K. (2001). Determinants of Chinese Consumers' Green Purchase Behavior. Psychology \& Marketing, 18(4), 389-413.

Chang, S. A. (2012). Time Dynamics of Overlapping E-Auction Mechanisms: Information Transfer, Strategic User Behavior and Auction Revenue. Information Systems Frontiers, 14(2), 331-342.

Chiu, C. M., Wang, E. T. G., Fang, Y. H., \& Huang, H. Y. (2014). Understanding Customers' Repeat Purchase Intentions in B2C E-Commerce: The Roles of Utilitarian Value, Hedonic Value and Perceived Risk. Information Systems Journal, 24(1), 85-114. doi: 10.1111/j.1365-2575.2012.00407.x

Cui, X., \& Lai, V. S. (2013). Bidding Strategies in Online Single-Unit Auctions: Their Impact and Satisfaction. Information \& Management, 50(6), 314-321.

Dang, C., Hu, Q., \& Liu, J. (2015). Bidding Strategies in Online Auctions with Different Ending Rules and Value Assumptions. Electronic Commerce Research and Applications, 14(2), 104-111.

Davis, F. D. (1989). Perceived Usefulness, Perceived Ease of Use, and User Acceptance of Information Technology. MIS Quarterly, 13(3), 318-323.

De Figueiredo, J. M. (2000). Finding Sustainable Profitability in Electronic Commerce. MIT Sloan Management Review, 41(4), 41-52.
Devaraj, S., Fan, M., \& Kohli, R. (2002). Antecedents of B2C Channel Satisfaction and Preference: Validating e-Commerce Metrics. Information Systems Research, 13(3), 316-333.

Du, H.S., Yu, H., Fang, Y., \& Wang, S. (2012). Empirical Investigation of EachNet: The ebay Model of C2C Online Auction in China. IEEE Transactions on Engineering Management, 59(1), 160-175.

Easley, R. F., \& Tenorio, R. (2004). Jumping Bidding Strategies in Internet Auctions. Management Science, 50(10), 1407-1419.

Easley, R. F., Wood, C. A., \& Barkataki, S. (2011). Bidding Patterns, Experience, and Avoiding the Winner's Curse in Online Auctions. Journal of Management Information Systems, 27(3), 241-268.

Einhorn, H. J., \& Hogarth, R. M. (1981). Behavioral Decision Theory: Processes of Judgment and Choice. Annual Review of Psychology, 32, 5388.

Elgharbawy, A., \& Abdel-Kader, M. (2013). Enterprise Governance and ValueBased Management: A Theoretical Contingency Framework. Journal of Management \& Governance, 17(1), 99-129.

Frankfort-Nachmias, C. N., \& Mias, D. (1996). Research Methods in the Social Sciences. (5th Ed.) London: St. Martin's Press, Inc.

Friesner, D., Bozman, C. S., \& McPherson, M. Q. (2008). Nibbling, Sniping, and the Role of Uncertainty in SecondPrice, Hard-Close Internet Auctions: Empirical Evidence from eBay. International Journal of E-Business Research, 4(1), 69-81.

Ghauri, P. N., Grønhaug, K., \& Kristianslund, I. (1995). Research Methods in 
Business Studies: A Practical Guide. Hemel Hempstead: Prentice Hall.

Gilkeson, J. H., \& Reynolds, K. (2003). Determinants of Internet Auction Success and Closing Price: An Exploratory Study. Psychology and Marketing, 20(6), 537-566.

Gonul, F. F., \& Leszczyc, P.T.L.P. (2011). Snipe Bidding Behaviour in ebay Auctions. International Journal of Electronic Marketing and Retailing, 4(1), 16-29.

Green, D. M., \& Swets, J. A. (1966). Signal Detection Theory and Psychophysics. New York: Wiley.

Hong, I. B., \& Cho, H. (2011). The Impact of Consumer Trust on Attitudinal Loyalty and Purchase Intentions in B2C EMarketplaces: Intermediary Trust vs. Seller Trust. International Journal of Information Management, 31(5), 469479.

Ivanova-Stenzel, R., \& Salmon, T. C. (2008). Robustness of Bidder Preferences among Auction Institutions. Economic Inquiry, 46(3), 355-368.

Jayaratne, T. E., \& Stewart, A. J. (1991). Quantitative and Qualitative Methods in the Social Sciences: Current Feminist Issues and Practical Strategies. In M. M. a. C. Fonow, J.A. (Ed.), Beyond Methodology: Feminist Scholarship as Lived Research. Bloomington: ndiana University Press.

Kamins, M. A., Dreze, X., \& Folkes, V. S. (2004). Effects of Seller-Supplied Prices on Buyers' Product Evaluations: Reference Prices in an Internet Auction Context. Journal of Consumer Research, 30(4), 622-628.

Kauffman, R. J., \& Wood, C. A. (2006). Doing Their Bidding: An Empirical Examination of Factors That Affect a Buyer's Utility in Internet Auctions. Information Technology and Management, 7(3), 171-190.
Kim, H. S. (2006). Using Hedonic and Utilitarian Shopping Motivations to Profile Inner City Consumers. Journal of Shopping Center Research, 13(1), 57-79.

Ku, G., Malhotra, D., \& Murnighan, J. K. (2005). Towards a Competitive Arousal Model of Decision-making: A Study of Auction Fever in Live and Internet Auctions. Organizational Behavior and Human Decision Processes, 96(2), 89-103.

Kumar, V., \& Subramaniam, V. (1997). A Contingency Framework for the Mode of Entry Decision. Journal of World Business, 32(1), 53-72.

Latane, B. (1981). The psychology of social impact. American Psychologist, 36(4), 343-356.

Lee, T. W. (1999). Using Qualitative Methods in Organizational Research. London: Sage.

Lowry, P. B., Cao, J., \& Everard, A. (2011). Privacy Concerns versus Desire for Interpersonal Awareness in Driving the Use of Self-Disclosure Technologies: The Case of Instant Messaging In Two Cultures. Journal of Management Information Systems, 27(4), 163-200.

Lowry, P. B., Gaskin, J., Twyman, N., Hammer, B., \& Roberts, T. (2013). Taking 'Fun and Games' Seriously: Proposing the Hedonic-Motivation System Adoption Model (HMSAM). Journal of the Association for Information Systems, 14(11), 617-671.

Lowry, P. B., Zhang, D., Zhou, L., \& Fu, X. (2010). Effects of Culture, Social Presence, and Group Composition on Trust in Technology-Supported Decision-Making Groups. Information Systems Journal, 20(3), 297-315.

Luthans, F. (1973). The Contingency Theory of Management: A Path out of the Jungle. Buiness Horizons, 16(3), 67-72. 
Luthans, F., \& Stewart, T. I. (1977). A General Contingency Theory of Management. Academy Management Review, 2(2), 181-195.

Mcdonald, C. G., \& Slawson, V. C. (2002). Reputation in an Internet Auction Market. Economic Inquiry, 40(3), 633650.

Mitchell, J. C. (1983). Case and Situation Analysis. The Sociological Review, 31(2), 187-211.

Namazi, A., \& Schadschneider, A. (2006). Statistical Properties of Online Auctions. International Journal of Modern Physics, 17(10), 1485-1493.

Onur, I., \& Tomak, K. (2006). Impact of Ending Rules in Online Auctions: The Case of Yahoo.com. Decision Support Systems, 42(3), 1835-1842.

Park, Y. H., \& Bradlow, E. T. (2005). An Integrated Model for Bidding Behavior in Internet Auctions: Whether, Who, When, and How Much. Journal of Marketing Research, 42(4), 470-482.

Pavlou, P. A., \& Gefen, D. (2004). Building Effective Online Marketplaces with Institution-Based Trust. Information Systems Research, 15(1), 37-59.

Petty, R. E., \& Cacioppo, J. T. (1986). The Elaboration Likelihood Model of Persuasion. Advances in Experimental Social Psychology, 19, 123-205.

Posey, C., Lowry, P. B., Roberts, T. L., \& Ellis, T. S. (2010). Proposing the Online Community Self-Disclosure Model: The Case of Working Professionals in France and the UK Who Use Online Communities. European Journal of Information Systems, 19(2), 181-195.

Puro, L., Teich, J. E., Wallenius, H., \& Wallenius, J. (2011). Bidding Strategies for Real-Life Small Loan Auctions. Decision Support Systems, 51(1), 31-41.
Quaddus, M., \& Achjari, D. (2005). A Model for Electronic Commerce Success. Telecommunications Policy, 29(2-3), 127-152.

Rafaeli, S., \& Noy, A. (2005). Social Presence: Influence on Bidders in Internet Auctions. Electronic Markets, 15(2), 158-175.

Raviv, Y. (2008). The Role of the Bidding Process in Price Determination: Jump Bidding in Sequential English Auctions. Economic Inquiry, 46(3), 325-341.

Rieskamp, J., \& Otto, P. E. (2006). SSL: A Theory of How People Learn to Select Strategies. Journal of Experimental Psychology: General, 135(2), 207-236.

Roth, A. E., \& Ockenfels, A. (2002). LastMinute Bidding and the Rules for Ending Second-Price Auctions: Evidence from eBay and Amazon Auctions on the Internet. American Economic Review, 92(4), 1093-1103.

Solberg, C. A. (2008). Product Complexity and Cultural Distance Effects on Managing International Distributor Relationships: A Contingency Approach. Journal of International Marketing, 16(3), 57-83.

Stern, B. B., \& Stafford, M. R. (2006). Individual and Social Determinants of Winning Bids in Online Auctions. Journal of Consumer Behaviour, 5(1), 43-55.

Strauss, A. L., \& Corbin, J. (1990). Basics of Qualitative Research: Grounded Theory Procedures and Techniques. Newbury Park, CA: Sage Publications.

Trevathan, J., \& Read, W. (2011). Disarming the Bid Sniper. Journal of Electronic Commerce Research, 12(3), 176-186.

Tsiotsou, R. (2006). The Role of Perceived Product Quality and Overall Satisfaction on Purchase Intentions. International Journal of Consumer Studies, 30(2), 207-217. 
Venkatesh, V. (1999). Creation of Favorable User Perceptions: Exploring the Role of Intrinsic Motivation. MIS Quarterly, 23(2), 239-260.

Wang, X., Yu, C., \& Wei, Y. (2012). Social Media Peer Communication and Impacts on Purchase Intentions: A Consumer Socialization Framework. Journal of Interactive Marketing, 26(4), 198-208.
Wilcox, R. T. (2000). Experts and Amateurs: The Role of Experience in Internet Auctions. Marketing Letters, 11(4), 363-374.

Wintr, L. (2008). Some Evidence on Late Bidding in eBay Auctions. Economic Inquiry, 46(3), 369-379. 


\section{Appendix: Interview Guide}

Note: This interview guide was designed to assist the interviewer. Follow-up discussions were added during the actual interviews. The sequence of the questions may not have been the same during the interviews due to different responses by the interviewees.

1. Background information:

$\checkmark \quad$ What websites do you usually bid in?

$\checkmark \quad$ Why do you choose auctions to buy things?

$\checkmark$ How many auctions have you won?

2. Bidding strategy:

$\checkmark \quad$ Jump bidding-Have you ever raised the price to a high level, even though it was not necessary according to the bid increment?

$\checkmark$ Ratchet bidding-Have you ever followed an auction and increased bids by the minimal bid increment?

$\checkmark$ Agent bidding-Have you ever assigned a bidding agent to bid for you?

$\checkmark \quad$ Snipe bidding-Have you ever just waited and only bid near the end of an auction?

$\checkmark \quad$ Sip-and-dipping-Have you ever bid for the first time at the early stage and then bid for a second time near the end of a multi-unit auction?

$\checkmark$ Are there any other bidding strategies that you have used?

This research aims to investigate the antecedents of online bidding strategies. Please recall the situations in selecting different bidding strategies and the reason why you adopted the bidding strategy in the following parts.
3. Bidding motivations:

$\checkmark$ Are you motivated to save money when bidding?

$\checkmark$ Are you motivated to save time when bidding?

$\checkmark \quad$ Are you motivated to obtain the item auctioned when bidding?

$\checkmark$ Are you motivated to enjoy the bidding process?

$\checkmark$ Do you have any other bidding motivations?

$\checkmark \quad$ For each kind of bidding motivation, what kind of bidding strategy have you applied? Do you think your bidding motivation will affect your bidding strategy selection?

4. Bidding mechanism:

$\checkmark \quad$ Do you think the bidding agent(s) used by the auction site(s) is (are) affective? Does its effectiveness affect your bidding motivation or bidding strategy?

$\checkmark$ Does the effectiveness of the feedback mechanism affect your bidding motivation or bidding strategy?

$\checkmark \quad$ Does the effectiveness of the escrow service affect your bidding motivation or bidding strategy?

$\checkmark \quad$ Does the effectiveness of the search engine affect your bidding motivation or bidding strategy?

$\checkmark$ Are you affected by the other bidders' bids? Does that influence your bidding motivation or bidding strategy?

$\checkmark$ Does the starting price affect your bidding motivation or bidding strategy?

$\checkmark \quad$ Does the bid increment affect your bidding motivation or bidding strategy? 
$\checkmark$ Do the ending rules affect your bidding motivation or bidding strategy?

$\checkmark$ Are there other environmental factors that will affect your bidding motivation or bidding strategy?

5. Product categories:

$\checkmark$ Is there any difference in your bidding motivation or your bidding strategy when you bid for new items or second-hand items?

$\checkmark$ Is there any difference in your bidding motivation or your bidding strategy when you bid for collectibles or merchandise?

$\checkmark$ Are there other different auctions that may affect your bidding motivation or bidding strategy?
6. Personal characteristics:

$\checkmark$ Do you think your bidding experience will affect your bidding strategy adoption?

$\checkmark \quad$ Is time very valuable for you or do you have much leisure time online? Do you think this will affect your bidding strategy?

$\checkmark \quad$ Are you are a risk-averse or riskseeking person? Do you think this will affect your bidding strategy?

$\checkmark$ Are there other personal characteristics that will affect your bidding motivation or bidding strategy?

7. Concluding questions:

$\checkmark \quad$ It seems there are a lot of factors that may influence bidding strategies. Besides those we have discussed, are there any other important things we have missed? 


\section{About the Authors}

Dr. Xiling Cui is an assistant professor in the department of Business Administration at the Hong Kong Shue Yan University. Her research interests include electronic commerce, online auctions, IT and innovation and knowledge sharing. She has published papers in Electronic Markets, International Journal of Electronic Business, International Journal of Information Management, and Information \& Management.

Dr. Lai Kuen Law, Shirley, is currently an Assistant Professor at the Department of Business Administration of Hong Kong Shue Yan University. Her research interests centre on human resource management, especially on work-family issues, and marketing strategy, particularly on Generation $Y$ and the hospitality industry. In addition, she is a chartered marketer of the Chartered Institute of Marketing (CIM). She has papers published in Journal of Management Systems, Marriage \& Family Review, and Asian Economic Review.

Dr. Paul Benjamin Lowry is a Full Professor of Information Systems at the Information Systems Department of the City University of Hong Kong. He received his Ph.D. in Management Information Systems from the University of Arizona and an MBA from the Marriott School of Management.
He has published $85+$ journal articles in MIS Quarterly, Information System Research, J. of Management Information Systems, J. of the AIS, Information Systems J., European J. of Information Systems, IJHCS, JASIST, I\&M, CACM, DSS, and many others. He is the co-editor-in-Chief of AIS-Transactions on $\mathrm{HCl} . \mathrm{He}$ is an SE at Decision Sciences and at JAIS (guest). He serves as an AE at Information Systems Journals, European Journal of IS, Information \& Management, Communications of the AIS, and the Information Security Education Journal. He has also served as an ICIS, ECIS, and PACIS track chair in various security/privacy tracks. His research interests include organizational and behavioral security/privacy issues; $\mathrm{HCl}$ and decision sciences; e-commerce and supply chains; and scientometrics.

Dr Qiuzhen Wang is an Associate Professor of Information Systems at Zhejiang University. Her research interest focuses on online consumer behavior and Human-Computer Interface $(\mathrm{HCl})$ design in $\mathrm{E}$-Commerce. She has papers published in Decision Support Systems, International Journal of Project Management, Electronic Commerce Research, Enterprise Information Systems, International Journal of Information Management, and other academic journals. 